\title{
PERSONAL CHANGE AS A KEY DETERMINANT OF THE OUTCOMES OF ORGANISATIONAL TRANSFORMATION INTERVENTIONS
}

\author{
THABILE CHAWANE \\ LJ VAN VUUREN \\ G ROODT \\ Programme in Industrial Psychology \\ Department of Human Resource Management \\ $R A U$ University
}

\begin{abstract}
The purpose of this study was to investigate the critical role of personal change, and its inherent elements, in determining the outcomes of organisational transformation interventions. The purposeful sampling method was used to involve expert organisational transformation consultants as participants $(\mathrm{N}=10)$. A qualitative content analysis technique was applied to infer meaningful explanations to the research problem. It was found that although personal change formed an integral part of transformation interventions, it was not adequately explored and utilised as a crucial and consequential dimension in influencing the results of organisational transformation interventions. The implications of the findings are discussed.
\end{abstract}

\section{OPSOMMING}

Die doel met hierdie studie was om die kernrol wat persoonlike verandering, en die elemente inherent daaraan, ten opsigte van die uitkomste van intervensies gerig op organisasietransformasie vertolk, te ondersoek. Doelmatigheidsteek-proefneming is aangewend om kundige organisasie-transformasie konsultante $(\mathrm{N}=10)$, wat moontlik die rol van persoonlike verandering tydens transformasie-intervensies verreken, as navorsingsdeelnemers te betrek. 'n Kwalitatiewe inhouds-ontledingstegniek is benut om betekenisvolle verklarings vir die navorsingsprobleem daar te stel. Daar is bevind dat hoewel persoonlike verandering ' $\mathrm{n}$ integrale komponent is van intervensies gerig op transformasie, dit nie genoegsaam as 'n deurslaggewende en vooruitspruitende dimensie van transformasie verreken en benut word nie. Die implikasies van die bevindinge word bespreek.

South Africa (SA) faces the challenge of becoming a global economic player. It is a challenge because of the unimpressive South African rankings reported in the World Competitiveness Yearbook (WCY) surveys (WCY, 2001; 2002). Several authors have stressed the country's obligation to become economically competitive among the world economies (Manning, 1997; Mbigi \& Mandela, 1998; Tonkin \& Alfred, 1994). Competitiveness and productivity are intertwined yardsticks of a nation's standard of living and are a result of the capacity of a country's organisations to achieve sustained economic productivity (WCY, 2001; Yadavalli, 1998). In cognisance of this need, the country has set herself the primary challenge to increase wealth creation (WCY, 2001).

The productivity of a country's workforce is a crucial component of the competitiveness factors forming the criteria in terms of which countries are evaluated (WCY, 2001). Accordingly, organisational transformation programs are pursued inter alia with the aim of improving the productivity levels of organisations, which is a logical precedent of national competitiveness. Veldsman (1998) and Yadavalli (1998) report that SA's competitiveness rankings have been consistently poor. The offered explanations generally attribute SA's organisational underperformance to a lack of insight and commitment to change programs; organisations which are not capable of learning and inflexible management thinking; neglect of the development of an organisation's people; and a lack of trust in workplace relationships that do not reflect the principles of fairness and organisational integrity, resulting in incongruent personal and organisational goals (Birkin, 1997; Erwin, 1998; Hall \& Maritz, 1997; Mbigi, 1997; Veldsman, 1996).

Cooper and Markus (1995), Bartlett and Ghoshal (1995), Ghoshal and Bartlett (1996), and Veldsman (2002) have noted the growing insight that the engine of organisational transformation

Requests for copies should be addressed to: T Chawane, Department of Human Resource Management, RAU University, PO Box 524, Auckland Park, 2006 lies in the people who do the work, through their attitudes, assumptions and behaviours as they fulfil their work-roles. The premise of this study is that organisational change approaches that have a primary emphasis on the dimension of personal change could result in individual excellence that in turn would lead to organisational productivity, wealth creation and national competitiveness.

Daft and Lengel (1998) and Veldsman (2002) explain personal change as a blending together of the inner world of the individual, consisting of the individual's thoughts and attitudes, feelings and spirit, with the outer world of the organisation, consisting of the trends, crises and competition. Nadler and Tushman's (1980) contention that organisational change programs are strategic efforts toward the creation of compatible organisational systems that would enhance effective organisational functioning displays a similar line of thought. Thus, the competitiveness levels referred to earlier and the cited factors for SA's economic underperformance compel a need for personal change in SA organisational members. This could influence the required organisational transformation and help South Africa to meet its challenges, while also improving national competitiveness levels.

Obholzer (1994) endorses that the need for change is selfevident and generally acknowledged, and argues that meaningful change is difficult to achieve. Erfat (1998), Human (1996), Manning (1996) and Werth (1994) also report that SA organisational change efforts have yielded minimal success. The authors ascribe this to the regrettable disregard of the significant dimension of personal change in organisational transformation approaches employed.

The ineffectiveness of change interventions

Czander (1993) and Diamond (1986) cite several conceptual foundations which affirm that individual employees have a basic, ongoing need to maximise their potential. Hersey and 
Blanchard (1993) refer to Abraham Maslow's hierarchy of needs, of which self-actualisation as a particular need explains man's ultimate life goal. This need pertains to individuals' desire to fulfil themselves as creative people according to their potentialities within the prevailing limitations of their reality. Self-actualisation implies personal mastery (Senge, 1990) and self-empowerment (Manning, 1997). The emphasis is on an individual's compelling urge to achieve through continuous psychological growth. An acknowledgement of this need with regard to personal change processes is critical if the interdependence of individuals' and organisational needs is accepted (Daft \& Lengel, 1998).

Organisational environments are expected to serve as the source of the required energies to fulfil individuals' needs. Halton (1994), however, asserts that organisations respond to challenges much like individuals. They develop defensive routines against difficult emotions which are too threatening or painful to acknowledge, while also inhibiting learning in the process (Argyris, 1985; 1990). The organisational strategies employed to diffuse the defensive routines result in structures which frustrate rather than satisfy individuals' needs (CoulsonThomas, 1992; Czander, 1993; Mbigi \& Maree, 1995). Since individuals' needs are dominant, they often compel employees to undermine the organisation's tasks to obtain selfgratification. Management frequently responds by increasing control, making threats and/or introducing reward schemes which are designed to force and/or entice employees to keep on working (Czander, 1993).

Czander's (1993) contention, and that of this study, is that organisational transformation programs are intended to restore a balance between the organisational needs of competitiveness and the individual's needs of personal goal satisfaction. As a result of that, and because of the dominant nature of individuals' needs over those of organisations, SA organisational change interventions should endeavour to realign organisational and individuals' needs (Coulson-Thomas, 1992; Czander, 1993; Diamond, 1986). The objective of this study is, therefore, to explore the phenomenon of personal change, its elements and their psycho-dynamic nature, as well as their hypothesised critical role in influencing effective organisational transformation programs. This objective seems justifiable in view of Stokes' (1994) reference to Reed and Palmer's (1972) assertion, that individuals' goal satisfaction comes not necessarily from changing the organisation. It also stems from individuals finding, making and taking a role in relation to the task and the organisational structures available to support those goals.
A review of five general organisational change models According to Nadler and Tushman (1980), organisational transformation models are aimed at depicting the interdependent factors that continuously interact to reflect organisational behavioural patterns. Burke and Litwin (1992) emphasise that models are not intended to prescribe, but rather to serve as frameworks for organisational diagnosis, planning and managing change.

The five general models were selected on the consideration that between them, they cover a) a diagnostic approach (Nadler \& Tushman, 1980); b) organisational performance and change (Burke \& Litwin, 1992); c) the dynamics of planned change (Robertson, Roberts \& Porras, 1993); d) an approach that focuses on individuals' tasks, roles, relationships and responsibilities; as well as on the significant role of organisational leadership (Beer, Eisenstat \& Spector, 1990) and; e) the imperative of the fairness perspective in enhancing individuals' adaptation to organisational change (Novelli, Kirkman \& Shapiro, 1995). These approaches represent a comprehensive overview of the different aspects of organisational change rather than a focus on the subprocesses contained in change approaches.

Reviewing the models will serve five distinct purposes for this study. Firstly, the process will make known the generic components of theoretical change models. Secondly, it will allow an assessment of the extent to which personal change elements are considered and/or emphasised in the identified components. Thirdly, it will facilitate the development of an objective framework by which the components of the researched SA change intervention models can be categorised. Fourthly, it will enable a process by which the various components can be synthesised into four broad dimensions. Lastly, it will provide the means by which the data to be gathered can be analysed, classified and tabulated.

\section{A congruence model of organisational behaviour}

The congruence model of organisational behaviour (Nadler \& Tushman, 1980) describes organisations as dynamic and complex total systems that can achieve effectiveness providing the subparts approach a state of congruence. It emphasises input factors, amongst which are the human resource. According to this framework, organisational transformation initiatives should acknowledge employees' needs, preferences and expectations, since these factors influence behaviour, especially with regard to task performance. The imperative is for organisational components to produce effectiveness through their alignment with the larger organisational environment and yield a state of congruence (Nadler \& Tushman, 1980).

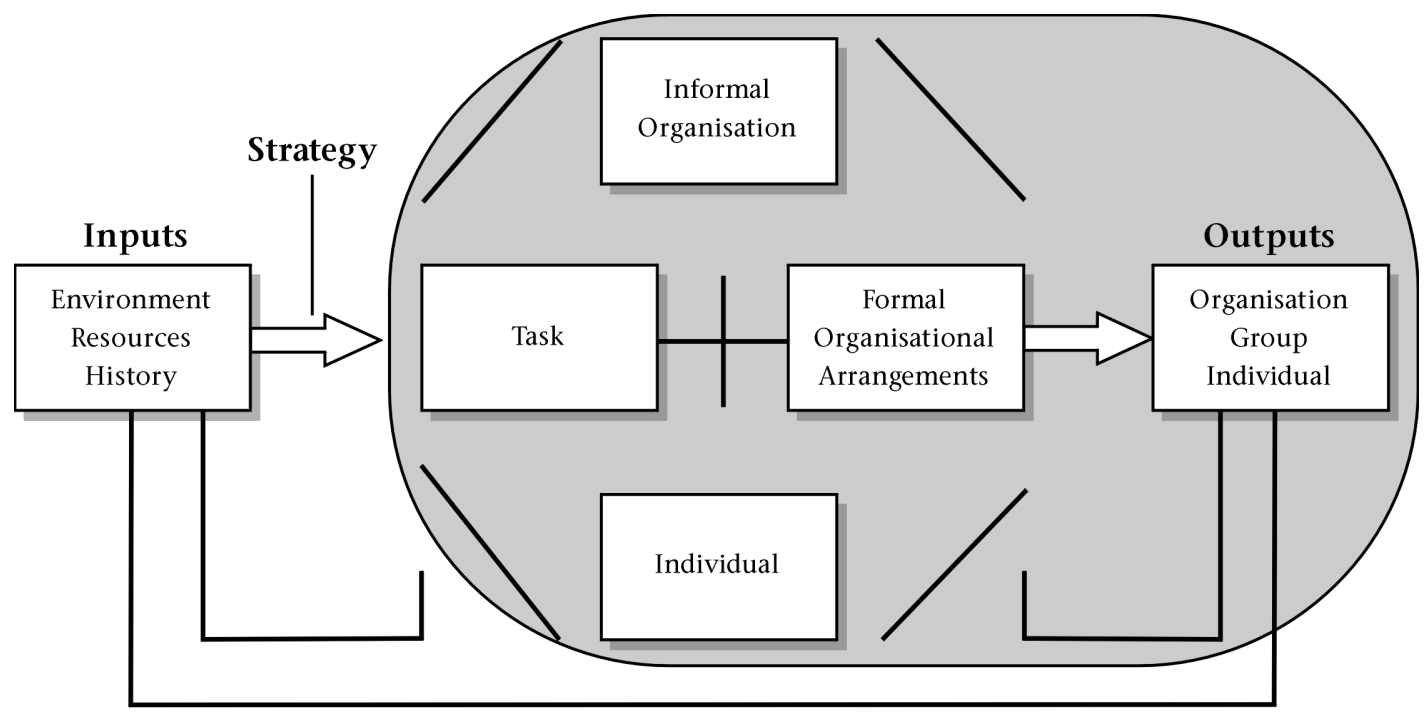

Feedback

Figure 1: A congruence model of organisational behaviour

(Nadler \& Tushman, 1980, p. 24) 
The Nadler and Tushman (1980) organisational framework neither applies particular emphasis on personal change elements, nor does it explain them as crucial components of organisational change initiatives. Instead, the authors explain that their model is general, diagnostic and descriptive of those factors that should be regarded as forming part of organisational systems. They recommend the development of specific sub-models that could be explored to deal with incongruity within particular organisational subsystems. Also, the authors cite the expectancy theory of motivation as a sub-model that could explain the fit between the component of 'individuals' and the other components of their model.

\section{A model of organisational performance and change}

The model of organisational performance and change (Burke \& Litwin, 1992) is founded on a functional cause and effect framework. It explains linkages that hypothesise how performance is affected as well as how deliberate and effective change can be influenced. The authors contend that the external environment affects transformational factors, which are identified as the organisational mission and strategy, leadership, and culture. These, in turn, affect transactional factors which are identified as the organisational structure, systems, management practices and climate. Both types of factors reciprocate and eventually impact on individuals' and organisational performance.

The model purports to integrate both organisational development and organisational change process theories to serve as a guide for diagnosis and planned, managed change. This integration is reported to clearly show cause and effect relationships between the organisation's internal and external environments in order to explain their link to organisational effectiveness (Burke \& Litwin, 1992). The authors mention that the identified transformational factors are the ones more weighty in bringing about fundamental organisational change, whereas the climate or transactional factors consisting of the employees' impressions, expectations and feelings, impact on organisational relationships. The reciprocity of the model components considered, the present study's assumptions question the 'more weighty' and 'more fundamental' explanation attributed to the transformational factors over the transactional factors.

\section{A theoretical model of the dynamics of planned organisational change}

According to Robertson, et al. (1993) the theoretical foundation of their model is that organisations are contexts within which individuals behave. The model explains how a climate of organisational alignment can be created to produce optimal productivity and performance. The model premises that an individual's behaviour is a primary determinant of both organisational performance and the level of an individual's development. Based on social cognitive models of behaviour, behaviour change is explained as the supposedly primary variable of focus (though not ultimate) for organisational change intervention. The model centres around four interdependent subsystems of work settings. These subsystems are regarded as variables that can be altered to induce change in an individual's behaviour with an intention to trigger organisational change.

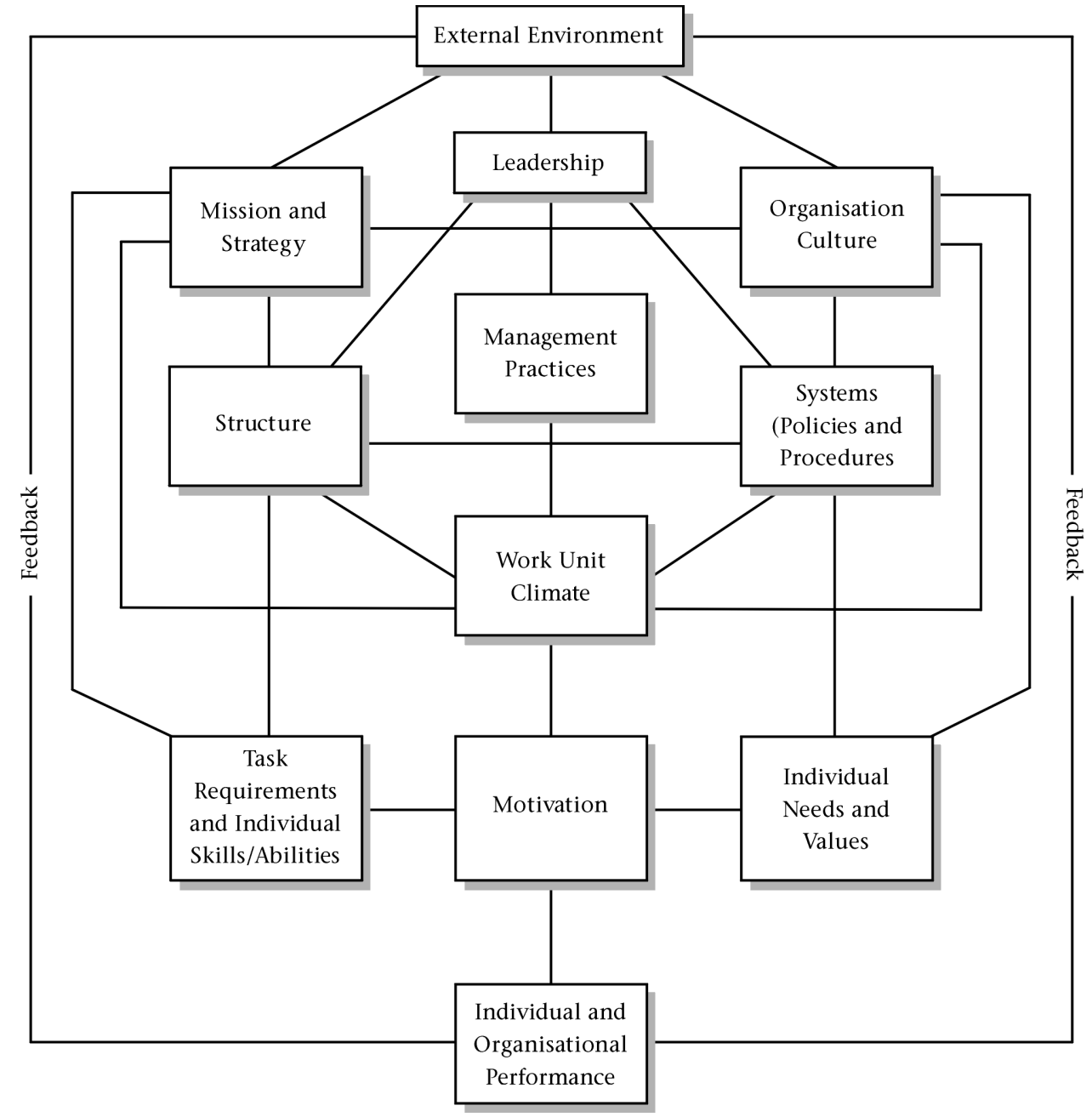

Figure 2: A causal model of organisational performance and change

Source: Burke \& Litwin, 1992, p. 7) 


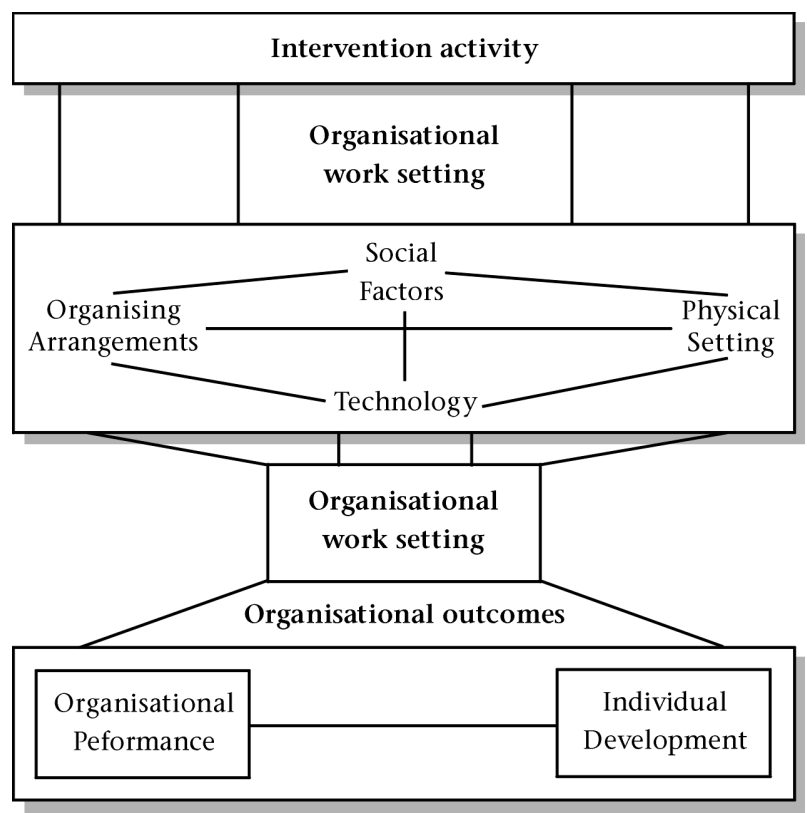

Figure 3: A theoretical model of the dynamics of planned organisational change

(Robertson, Roberts \& Porras, 1993, p. 621)
The explanation of the model focuses on demonstrating the significance of planned change in as far as it can facilitate systematic monitoring of a guided and effective organisational change process (Robertson, et al. 1993). Importantly, the model acknowledges personal change elements by recognising that individuals' work behaviours are also driven by factors outside an organisation. These factors are said to be crucial because they mediate the relationship between changes in the work setting, as well as organisational performance and individual development. The authors recommend a more explicit focus on a common set of behaviours which would provide a common denominator for a finer-grained analysis of the relationship among changes in work setting, individual behaviour and organisational outcome variables.

\section{A six-steps-to-effective-change framework}

The Beer, et al. (1990) framework is based on the rationale that organisational change, referred to as revitalisation, is a process that should be led by general managers within their respective organisational work units or divisions. The informal organisational arrangements, encompassing employee roles, responsibilities and relationships need to be aligned to the organisation's competitive task.

Task alignment is attained through a sequential process of six basic managerial interventions, and referred to as the critical path. The critical path is based on the belief that a change

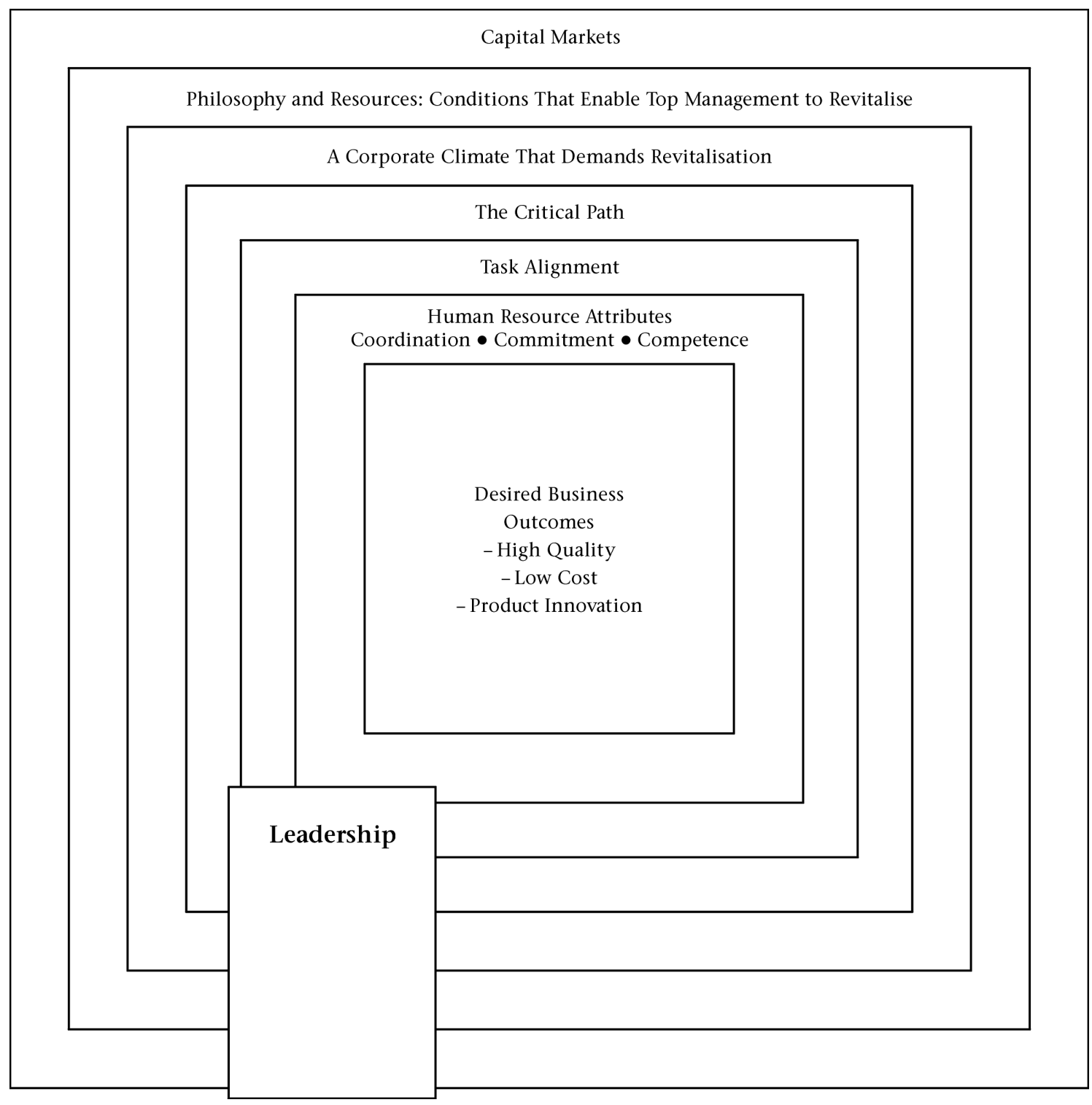

Figure 4: A six-steps-to-effective-change framework 
process that focuses on task alignment, which begins at the organisation's periphery, and progresses steadily toward the corporate centre, is the most effective way to achieve lasting organisational change (Beer, Eisenstat \& Spector, 1990).

According to Beer, et al. (1990) the success of the six steps to effective change program hinges on three interrelated factors. They are co-ordination, commitment and competencies. Although the discussed change program approaches change from the perspective of informal organising arrangements within organisational units, the authors maintain that top management has a responsibility to support such initiatives. Highlighted as part of the required support is the creation of a market for change, the promotion of revitalised units as models for the whole organisation, and the importance of developing career paths that encourage leadership development at the unit level and across the organisation.

The success of the six-steps-to-effective-change framework is substantiated by the results of the field research conducted by Beer, et al. (1990). However, their approach contrasts with the assumptions of this study. The authors view change intervention programs as effective if implemented at the work units/divisions level, thereby influencing individuals' desired attitudes and behaviours. Contrarily, this study's rationale regards change as effectual if approached in terms of the individual's internal cognitive and affective domains. These are regarded as areas within which internal learning processes take place, have an influence on decision making, and therefore shape behaviour.

\section{A six-step-framework of organisational justice for organisational change}

Novelli, et al. (1995) incorporated a justice perspective into Beer, et al. (1990) six-step-model in order to develop a six-stepframework-of-organisational-justice-for-organisational-change. Their approach emphasises the importance of organisational justice in enhancing the understanding and design of effective organisational change processes.
Novelli, et al. (1995) support the Beer, et al. approach because of the perceived difficulty that goes with implementing successful and effective organisational change. The redesigned approach is still based on six steps but incorporates the justice perspective on the change requirements made to employees. Both planning and correct sequencing of the steps are emphasised as crucial. Novelli, et al. (1995) indicate two primary implications of their model: a) the need to change organisations so that they are fundamentally more just; and b) the need for managers to change themselves so that they are more sensitive to justice issues.

The distributive, procedural and interactional justice issues are dealt with and resolved singly and jointly throughout the six steps to ensure effective implementation (Novelli, et al. 1995). Overall, the authors highlight the need for organisational leadership to achieve appropriate levels of self-awareness. This may assist in narrowing the gap between possible inconsistencies in organisational transformation endeavours. They strongly emphasise a deep level of personal transformation to create shifts in large behavioural patterns. The model descriptors solidify the argument for change approaches that recognise the depth required to explore the dimension of personal change.

\section{Personal change elements detectable in the reviewed theoretical models}

Common across the preceding organisational transformation frameworks is the use of purposeful, systematic yet dynamic, detectable and interdependent organisational components (Beer, et al., 1990; Burke \& Litwin, 1992; Nadler \& Tushman, 1980; Novelli, et al. 1995; Robertson, et al. 1993). Each model focuses on a preferred approach rather than to compare the varying degree of importance of each component. Personal change elements are acknowledged as forming part of the model components because other organisational factors impact directly or indirectly on organisational members. However, none of the models give particular focus or

TABLE 1

A SIX-STEP-FRAMEWORK OF ORGANISATIONAL CHANGE

Type of justice

\begin{tabular}{|c|c|c|c|}
\hline Change-model step & Distributive & Procedural & Interactional \\
\hline Jointly diagnose the business problem & $\begin{array}{l}\text { Will employees perceive that the } \\
\text { diagnosis is fair, or that it is biased? }\end{array}$ & $\begin{array}{l}\text { Will employees perceive that they have } \\
\text { input into the diagnostic process? }\end{array}$ & $\begin{array}{l}\text { Will employees perceive that } \\
\text { management listens to their expressed } \\
\text { views? }\end{array}$ \\
\hline $\begin{array}{l}\text { Develop shared vision of how to } \\
\text { organize for competitiveness }\end{array}$ & $\begin{array}{l}\text { Will employees perceive that the newly } \\
\text { developed shared vision provide them } \\
\text { with fair outcomes? }\end{array}$ & $\begin{array}{l}\text { Will employees perceive that they have } \\
\text { input into how the company will } \\
\text { organize for competitiveness? }\end{array}$ & $\begin{array}{l}\text { Will employees perceive that } \\
\text { managers listen to and respect employee } \\
\text { questions and concerns regarding } \\
\text { the shared vision? }\end{array}$ \\
\hline $\begin{array}{l}\text { Create consensus, competence, and } \\
\text { the cohesion needed for change }\end{array}$ & $\begin{array}{l}\text { Will employees perceive that the support } \\
\text { mechanisms (i.e. training, outplacement } \\
\text { assistance) generate fair outcomes? }\end{array}$ & $\begin{array}{l}\text { Will employees perceive the criteria } \\
\text { by which some of them are retained } \\
\text { and others are terminated as fair? }\end{array}$ & $\begin{array}{l}\text { Will employees perceive that } \\
\text { managers act with empathy and } \\
\text { sensitivity regarding those who } \\
\text { remain and those who do not remain } \\
\text { in the organization? }\end{array}$ \\
\hline
\end{tabular}

Don't push the changes from the top Will employees perceive that new roles, responsibilities, and authority are fair outcomes?

Institutionalize the change

Monitor and adjust the change process
Will employees perceive that their outcomes resulting from the institutionalized policies, systems, and structures are fair?

Will employees perceive that the outcomes generated by the monitoring and adjustment phases are fair?
Will employees perceive that they have a voice in determining changes in departmental roles and responsibilities that must accompany the overall change process?

Will employees perceive that they have a voice in determining what changes are made permanent and what changes are not?

Will employees perceive that the monitoring and adjusting of the change process is fair and that they get to express voice in these matters?
Will employees perceive that sincere and adequate explanations are provided about their changing roles and responsibilities as a result of the change?

Will employees perceive that sincere and adequate explanations are provided regarding which changes are institutionalized and which are not?

Will employees perceive that managers listen to and respect the results of the employees' monitoring and adjusting activities? 
emphasise the critical role of the dimension of personal change in influencing effective organisational change. Consequently the phenomenon and its elements still remain unexplored as key source of the required energy to propel individual task performance toward excellent organisational productivity.

\section{THE CONCEPTUAL FOUNDATIONS OF THE CONCEPT "PERSONAL CHANGE"}

According to Cutcliffe (2000), the literature review methid is a legitimate initial process in a qualitative study in that it enhances conceptual clarity. It also increases the conceptual density and the richness of concept development. According to Backman and Kyngas (1999) literature analysis also facilitates the narrowing down of the research problem. Personal change is a concept that belongs to the spheres of the subconscious and intuitive (Senge, 1990). Its impact is however, acknowledged by several authors, including Covey (1991), Daft and Lengel (1998), Manning (1997), Quinn (1996) and Veldsman (1998).

Personal change factors are described as key elements in individuals' relationship formation with their co-workers and their workrole identification. They are divided into the cognitive and affective domains. Czander (1993), Diamond (1986) and Herzberg (1971) describe these factors as the psychodynamic elements of an individual's behaviour. The authors explain them as powerful unconscious motives which have an influence on work performance. Block (1996) contends that personal change factors cannot be dealt with at a concrete level to deliberately yield the desired organisational transformation. However, the author's contention, in line with that of Senge (1990), is that a focus limited to the concrete is a traditional organisational practice which would never result in competitive and adaptable organisations. A large part of organisational concerns can only be satisfied through a conscious seeing and a re-evaluation of the people's intangible needs, wants, longings and expectations. All subtle phenomena which, according to Diamond (1986), will obstruct learning and change if ignored.

Czander (1993) insists, however, that it is important to understand personal change factors. The author furthermore contends that psychoanalytic theories should be considered to enrich organisational theorising in order to understand the key elements that contribute in making work a meaningful experience that can increase individual excellence and organisational productivity. This opinion is strongly supported by Mosse (1994), who suggests that the organisational theories and psychoanalytic perspectives on change must be used together if real change is to be effected.

Czander (1993) and Mosse (1994) conclude that if one of the perspectives is to be used without the other, the change effort will fail. Personal change elements should therefore be incorporated into and drawn from, to develop comprehensive organisational transformation models. Table 2 provides a broad framework to identify the personal change dimension, components and elements as well as the domains they occupy (Covey, 1991; Daft \& Lengel, 1998; Forsha, 1992a; Hey \& Moore, 1998; Veldsman, 2002). The included questions provide guidelines that an individual may use to evaluate one's personal change requirements.

\section{The approaches to change}

Marshak (1993) distinguishes between developmental, transitional and transformational change. In the same vein, Swart and Van Vuuren (1998) refer to Spicer's (1989) change strategies, which explain the difference between incremental and quantum change. The former is explained as referring to organisational efforts to change present mechanisms by doing more of the same, whereas the latter refers to a paradigm shift, incorporating new values and behaviours. Since the intangible personal change elements are centred at the cognitive and affective levels of an individual's psycho-dynamic system (Czander, 1993; Long \& Newton, 1997), they are, therefore, suggestive of transformational and/or quantum change.

Ivancevich and Matteson (1993) have a similar contention. They identify ten levels of change targets which vary according to the depth of intended change required from the individual and organisation. Level one represents the shallowest change and level ten represents the deepest depth of required change. Personal change as the subject of the present study falls within level nine (individual behaviour) and level ten (individual/group behaviour). These levels target the deepest level of individual's behavioural change. Novelli, et al. (1995) state that personal change is not only about changing a few behaviours but rather that it is about a deep level of personal work that creates shifts in large behavioural patterns. The emphasis is on appropriate attempts to adequately address individuals' deeply embedded behavioural patterns without dismissing them as resistance to change (Argyris, 1985; 1991; Czander, 1993; Halton, 1994; Long \& Newton, 1997; Mosse, 1994).

TABle 2

The Dimension of Personal Change

\begin{tabular}{|c|c|c|c|}
\hline Component & Element & Domain & Types of questions to prompt individuals to change \\
\hline Mindfulness & $\begin{array}{l}\text { Independent thinking, creativity } \\
\text { assumptions, open-mindedness }\end{array}$ & Mind & $\begin{array}{l}\text { How competent am I in my task performance? How open am I to learning? } \\
\text { How creative am I in my task performance? Am I satisfied with my performance? }\end{array}$ \\
\hline Vision & $\begin{array}{l}\text { Striving for higher purpose in task } \\
\text { performance }\end{array}$ & Mind & $\begin{array}{l}\text { How do I foresee myself bringing about a change in my work? How can I do } \\
\text { my work to the best of my abilities }\end{array}$ \\
\hline Heart & $\begin{array}{l}\text { Caring and compassionate attitudes, } \\
\text { nurturing relationships with } \\
\text { colleagues }\end{array}$ & Emotion & $\begin{array}{l}\text { How passionate am I about my work? Am I enthusiastic about my work? Do } \\
\text { I care about how my work affects team members, the customers and the } \\
\text { organisation? Does my work fulfill me? }\end{array}$ \\
\hline Communication & $\begin{array}{l}\text { Expresses the vision, values, beliefs, } \\
\text { emotions and commitment }\end{array}$ & Emotion & $\begin{array}{l}\text { Am I meeting quality expectations which support the vision and mission? Is } \\
\text { my performance supportive and shows a commitment to the vision and mission? }\end{array}$ \\
\hline Courage & $\begin{array}{l}\text { Risk taking, non-conformity, } \\
\text { a willingness to take initiative } \\
\text { leading to learning and growth }\end{array}$ & Spirit & $\begin{array}{l}\text { Can I risk bringing about innovation and improvement to my work? Do I have } \\
\text { the scope to explore and implement what I think my task requires? What will } \\
\text { it take for me to act on my desire to improve? Do I want to do that? What is in } \\
\text { it for me as a person? }\end{array}$ \\
\hline Integrity & $\begin{array}{l}\text { Honesty, trustworthiness, being of } \\
\text { service to others, the team and the } \\
\text { organisation, acknowledging stated } \\
\text { and unstated norms }\end{array}$ & Spirit & $\begin{array}{l}\text { Am I sincere in my task performance? Am I doing it to the best of my abilities? } \\
\text { Am I proud and satisfied with the contribution I am making in meeting my } \\
\text { needs and those of the organisation? Can I be relied upon to deliver the best } \\
\text { work through my work roles/tasks? }\end{array}$ \\
\hline
\end{tabular}


According to Czander (1993) personal change requires a method of engagement that can bring about any learning or creativity toward personal renewal. This point of view is supported by Obholzer (1994) who identifies three layers of anxieties. These are primitive anxieties, anxieties arising out of the nature of the work, and personal anxieties. The author stresses the need for organisations to understand and contain these layers of anxieties within individuals before change can be managed. Such an approach would curtail the futility of attempting to solve irrational organisational problems, which stem from individuals' irrational dynamics and motives, with rational methods. The latter approaches only result in dysfunctional organisational systems which perpetuate a simplistic notion of the requirements of organisational transformation challenges (Czander, 1993).

\section{The process of personal change}

In tracing personal change processes, Bretherton, (1993), Bridges (1996), Forsha (1992b) and Hey and Moore (1998), agree that the individual's awareness of the need to commence self-change is the first most important occurrence because it influences further all required change phases and activities. It requires a disciplined commitment to self-reflection and contemplation about the values and purposes of one's life, which will result in the desire and willingness to change oneself (Edwards \& Sen, 2000). Both Czander (1993) and Long and Newton (1997) strongly suggest that the psycho-dynamic approach should be explored as a possible means by which the individual's creative energies can be unlocked. Through such efforts an individual's internal thought processes can be brought to a conscious state of awareness. It could provide a base from which a general understanding about the relationship between an individual and his environment can be formulated. A different paradigm of thinking would also result in constructive interpretations of which change path to pursue (Forsha, 1992a).

The continuous personal renewal path further creates a loss of control and leads to fearfulness, anxiety, denial, numbness, confusion, anger, depression and finally, acceptance of the implications and goals of the change requirements (Bretherton, 1993; Buckham, 1996; Forsha, 1992a; Hey \& Moore, 1998; Quinn, 1996).

These responses are associated with Czander's (1993) and Diamond's (1986) explanations of affective and cognitive processes of change which are based on psycho-dynamic interventions to personal change. George (2000) relates these processes to Forgas' Affective Infusion Model which states that feelings and emotions have an influence on thinking processes, judgement and on decision-making. These complex affective responses are internal learning experiences through which extensive reflection, accurate judgement, constructive learning and evaluation occur which shape required behaviours (Long \& Newton,1997).

\section{The contextual requirements for personal change}

Long and Newton (1997) assert that organisations are required to be reliable, safe learning environments which would provide psychological conditions for self-management of one's tasks, decisions and accountability. Such environments make provision for the inherent individual differences which are continuously at play in work-places. The effects and counter-effects between peers, subordinates and super-ordinates, and the restrictive organisational contexts within which they take place, are determinants of an individual's readiness to accept the imperative of personal change processes (Long \& Newton, 1997).

Covey (1993), Daft and Lengel (1998), as well as Manning (1996), infer that only when both the organisational and individual dimensions are acknowledged and aligned, can individuals succeed in developing ways of understanding their organisational systems, and be able to determine their own roles in steering the organisation toward a state of productivity and competitiveness. Both organisational leadership and organisational culture should succeed in triggering the desire, and influence a need for personal change. Accordingly, productivity cannot be pursued as an end in itself. It should, instead, be a by-product of an individual's identification with organisational goals which result from the achievement of the individual's goal of self-worth through self-discovery processes (Long \& Newton, 1997). When the environment is conducive, organisational members would individually and collectively experience less anxiety about their work and their relationships (Daft \& Lengel, 1998).

They would take collective responsibility towards problemsolving in a manner that would optimise the organisation's efficiency and effectiveness. They would also gain improved senses of self by acquiring a clearer understanding of the boundaries between themselves and the environment. This would enhance self reliance and engender mental freedom to take risks (Argyris, 1991).

The research question in the present study seeks to investigate the extent to which personal change and its elements are emphasised in SA organisational transformation intervention programs. The goal is to explain personal change as a catalytic organisational dimension requiring prominent and significant prevalence in organisational transformation intervention programs. The findings of the study may, therefore, provide explanations regarding its role as a critical determinant on the success-failure continuum of organisational transformation interventions.

\section{METHOD}

According to Kerlinger and Lee (2000), the main criterion of a research design is that it should adequately answer the research question. Annels (1996) supports this assertion by stating that the research question(s) serve to sensitise the research problem to the field of investigation from which hypotheses are developed to be tested against the data to be collected. The research question to be investigated therefore suggests that the incorporation of personal change is expected to vary within and between the intervention programs to be evaluated. Furthermore, the word 'extent' in the research question implies that the depth of meaning attributed to the concept, as would be derived from the responses, will also vary.

The first assumption, therefore, is that a research method that can allow a varying degree of explanation of the researched concept and depth of inferred meaning from the collected data has to be employed. The second assumption is that the study qualifies as qualitative in that the meaning to be attached or inferred to the concept will be derived from an analysis of words, phrases and themes as they emerge from the responses. The qualification of the study as qualitative is supported by Silverman (2000) who asserts that such studies are commonly believed to provide a deeper understanding of the phenomenon being investigated.

Silverman's (2000) assertion is pertinent in that personal change as a hypothesised catalytic dimension necessitates clarity of meaning before its influence in organisational transformation interventions can be ascertained. The third assumption is that, because the resulting communication between the researcher and the respondents is to be in a text format, content analysis (Babbie \& Mouton, 2001) seems a suitable method. This method allows for the tapping of the latent and underlying meaning as may be deduced from the collected data. Content analysis is also found suitable because it can assist in identifying the distinctive elements of a text from which an inference can be made (Hicks, Rush \& Strong, 1977). Thereby, unearthing the essence of expressions as a whole, while also reconstructing the substantive meaning by interpreting it (Roller, Mathes \& Eckert, 1995). 
Babbie and Mouton (2001), Berg (2001) and Roller, et al. (1995) highlight that content analysis can also be successfully applied to quantitative studies. The differentiating factor is that in a quantitative application, the procedure of analysis is of concern, whereas in a qualitative application the concern is the character of the available data (Berg, 2001). In quantitative approaches, a complexity of whole messages are reduced to single elements whose frequency can be counted, whereas qualitative approaches seek to identify the meaning of a message as a whole from which interpretations can be made (Roller, et al., 1995). This means that quantitative content analysis can be applied to large quantities of messages whereas the qualitative approach is confined to smaller quantities. The fourth and last proposition is that because qualitative content analysis is suited to smaller quantities of messages, it becomes an ideal approach for the present study, given that the data sources were deliberately narrowed.

Although content analysis has a subjective leaning, Hicks, et al. (1977) maintain that the meanings to be determined have to be an accurate inference of the intention of the message sources. This view is upheld by Berg (2001) who identifies a sequential set of analytic activities which can be employed to ensure a rounded application of content analysis techniques. Accordingly the author points out that an objective coding system has to be applied to the data so that categorical labels or themes can be formulated to exhaustively account for each variation of the content of messages. The theoretical model components will hence form the basis of the coding method to be used in developing categories for classification and data analysis for this study.

It should be noted that focus group interviews or interview schedules (Berg, 2001) with the identified participants would have been equally suited for the present study. However, limitations pertaining to the nature of the work performed by consultants within consulting firms (accessibility, irregular hours and costs of consulting fees) meant that time constraints and financial resources (of the researcher) necessitated a method that impacted minimally on these resources. Content analysis, therefore, became a preferred method that provided a feasible approach within the constraints of the study.

\section{Participants}

A purposive sample (Huysamen, 1994) comprising 15 reputable organisational development and transformation management consultants, within their consulting firms, were approached for the present study. Their selection was based on the level of their knowledge and expertise in organisational change and transformation management. One respondent, however, described the scope of their firm's operation as in competitive strategy development rather than in organisational transformation management. The sample size represented a significant proportion of SA consulting firms ranging in size from small (about 10 members) to very large international consulting firms of about 14000 professionals, some of whom serve more than a third of the companies in the Global Fortune 500.

Ten consultants representing their respective firms responded. Five consultants did not respond by the time of results' analysis. Eight of the respondents presented their organisational transformation intervention programs as comprehensive tools within their firms' approaches rather than individuals' approaches to change interventions. The other two described their programs as their own individualised approaches to change intervention and management. Nevertheless, all the contributions are regarded as sufficient because they are representative of very large and well-established management consulting firms.

\section{Measuring instrument}

The following two open-ended questions were carefully formulated and put to the respondents:
- "Please identify and briefly explain the key components of the generic model(s) and/or approach(es) that you prefer to use as a consultant in organisational transformation interventions in South Africa. Please feel free to attach or fax any relevant material (e.g. model or process) which may enhance our understanding of your approach."

- "Please explain the extent to which your firm's organisational transformation interventions make provision for personal change of individuals in the client organisations. Also indicate whether personal change is a critical determinant of the interventions' success or failure."

- The first question was asked to establish whether SA organisational transformation intervention processes incorporated and focused on personal change as a component in their models. The second question was asked to determine the impact personal change had on the outcome of organisational transformation interventions.

\section{Procedure}

The consultants identified were contacted at the consulting firms they worked for and could be reached with minimal effort. Initial contact was conducted telephonically to establish their availability and willingness to participate in the research study. They confirmed these by making available (upon request) their electronic-mail addresses. The latter medium of contact was used to send the research questions. A covering letter was attached, the purpose of which was to assure the participants of their anonymity and to convey the respect with which their confidentiality and their contributions will be treated. A solicited document in the form of an essay was received from the respondents via e-mail.

\section{Data analysis}

Table 3 was formulated by integrating and using the reviewed theoretical models' components as sources/derivation for the various categories. The first column categorises the various components according to how the theoretical models commonly refer to them. The second column categorises the broadly formulated phases/dimensions according to the seeming linkages among all the theoretical models' components. These broad dimensions will provide means by which the researched models' components can be analysed and tabulated. The last column identifies the theoretical models' components as they are given in the table/figure they derive from.

Tables 4 to 7 were designed to illustrate and structure the analysis of the data received in response to the first research question. The targeted unit of analysis for the study were the consulting firms although individual consultants responded on behalf of their firms. The first column of each Table is coded 'Respondent' and each row is arbitrarily but consistently labelled with a number from 1 to 10 to represent each responding firm. Other columns are each prominently coded with a theoretical component. The statements and phrases given as responses and which seemed to describe a process associated with each theoretical component, were classified accordingly. Table 8 illustrates and structures the analysis of the data received in response to the second research question.

The foregoing procedure used to formulate the tables is explained to ensure the reliability of the data analysis process. Importantly, the statements and phrases recorded in the tables are quoted verbatim from the responses to meet the internal validity requirements for the present study. The coding, categorising and classification of the data from the responses were strictly done according to the procedure described above in order to facilitate any future replication of the study. From the descriptions given in the responses, meaningful inferences were established and discussed as findings of the present study. 
TABLE 3

Formulation OF CATEgories, PHASES/DIMENSIONS FOR DATA ANALYSIS

\begin{tabular}{|c|c|c|}
\hline Derived category & Derived phase/dimension & Theoretical components \\
\hline Diagnosis & Scanning and diagnosis phase & $\begin{array}{l}\text { Jointly diagnose business process, environment, resources, } \\
\text { history, mobilising energy }\end{array}$ \\
\hline Vision & Scanning and diagnosis phase & $\begin{array}{l}\text { Develop shared vision of how to organise for } \\
\text { competitiveness }\end{array}$ \\
\hline Mission and strategy & Scanning and diagnosis phase & Strategy and mission \\
\hline $\begin{array}{l}\text { Task requirements, training and competencies, } \\
\text { skills and abilities }\end{array}$ & Performance and rewads requirements dimension & $\begin{array}{l}\text { Create consensus, competence and cohesion needed for } \\
\text { change. Don't push change from the top, individual } \\
\text { abilities }\end{array}$ \\
\hline Systems, policies, management practices & Performance and rewads requirements dimension & $\begin{array}{l}\text { Management practices, systems, policies and procedures, } \\
\text { consolidating systems }\end{array}$ \\
\hline $\begin{array}{l}\text { Structure, formal organising arrangements, } \\
\text { physical setting, technology }\end{array}$ & Organisational infrastructure dimension & $\begin{array}{l}\text { Institutionalise the change, structure, physical setting, } \\
\text { technology, formal organisation }\end{array}$ \\
\hline $\begin{array}{l}\text { Oganisational culture, informal organisation, } \\
\text { work unit climate, social factors }\end{array}$ & Organisational infrastructure dimension & $\begin{array}{l}\text { Informal organisation, organisational culture, work unit } \\
\text { climate }\end{array}$ \\
\hline $\begin{array}{l}\text { Leadership philosophy, role and style, } \\
\text { resources for revitalisation }\end{array}$ & Organisational infrastructure dimension & Leadership \\
\hline $\begin{array}{l}\text { Individual motivation, behaviour, needs and } \\
\text { values }\end{array}$ & Desired targeted output phase & $\begin{array}{l}\text { Individual/group, organisation, motivation, individual } \\
\text { needs, values and behaviour, human resources attributes }\end{array}$ \\
\hline $\begin{array}{l}\text { Individual and organisational performance } \\
\text { outcomes }\end{array}$ & Desired targeted output phase & $\begin{array}{l}\text { Monitor and adjust the change process, desired business } \\
\text { outcomes }\end{array}$ \\
\hline
\end{tabular}

\section{RESULTS}

Eight of the responses were in plain text format and two incorporated both plain text and some graphic illustrations. The entire data source(s) were utilised and exhausted to maximise total coverage of the pertinent aspects of the research problem. In response to the request to identify their firms' generic model(s) and/or approaches, two respondents identified their firms' intervention programs as 'approaches'.

Three consultants identified their firms' intervention programs as 'models' with one of these named 'Organisational Transformation Model'. One identified their firm's intervention program as a 'Competitive Organisational Strategy'; one identified their firm's intervention program as a 'Change Navigation Strategy'; one identified their firm's approach as an 'intervention'; one identified their firm's intervention approach as 'principles'; and the last one identified their firm's intervention program as 'main steps'. Six of the ten respondents stated that their firms' models/approaches were based on practical experience which was customised to meet the client organisations' needs. Three stated that their firms' approaches were based on theoretical change models. The response to the first question of one of the ten respondents could not be evaluated, as the consultant's model was not received for analysis. All the models/approaches were explained as based on world-wide leading expertise and proven best practices in the field of organisational transformation management.

Since the formulation of categories was derived from the reviewed general models' key components, the resulting columns enabled the classification of the consulting firms' key components. Recorded thereunder are verbatim statements given in response to a request for brief explanation(s) of each model/approaches' key components. They are classified according to the degree of similarity in meaning between the theoretical and respondents' key models' components. One of the responses was not accompanied by the model's content, and, therefore could not form part of the analysis of results to the first question. The resulting data was, therefore, formatted and presented as Tables 4 to 7 .

Accordingly, Table 4 shows the scanning and diagnosis phase of the theoretical models. The first column reflects the range of statements used to explain the readiness assessment process at the onset of the change intervention process. Seven respondents alluded to that this process formed a key component of their intervention programs, whereas four of the theoretical models explicitly stated that 'diagnosis' formed a component of their frameworks. The second column reflects that four respondents had 'vision' as a key component of their change programs, whereas two theoretical frameworks had it as a distinguishable component. The third column reflects that six respondents stated that 'mission and/or strategy' formed a key component of their change programs, whereas three of the theoretical frameworks visibly identified the component.

It should be noted that within this phase, the 'external environment' component formed part of three theoretical frameworks, whereas, none of the respondents explicitly identified it as a component in their model.

Table 5 captures the organisational infrastructure dimension of the theoretical models. The first column indicates that six respondents explicitly stated that the 'formal organising arrangements and the physical setting' was a key component of their change programs, whereas all five of the theoretical frameworks explicitly identified the component. The second column reflects that three respondents had 'organisational culture, informal organisation, work unit climate and other social factors' as a key component of their change intervention programs, whereas all five of the theoretical frameworks identified it as a visible component. The third column indicates that six of the respondents stated that 'leadership philosophy, role and style' formed a key component of their change intervention programs, while all five of the theoretical frameworks identified it as a component. 
TABLE 4

SCANNING AND DIAGNOSIS PHASE

\begin{tabular}{|c|c|c|c|}
\hline \multicolumn{2}{|c|}{ Respondents diagnosis } & \multirow{2}{*}{$\begin{array}{l}\text { Vision } \\
-\end{array}$} & \multirow{2}{*}{$\begin{array}{l}\text { Mission \& strategy } \\
\text { "Project plan" }\end{array}$} \\
\hline 1 & $\begin{array}{l}\text { "Problem identification, need for change, } \\
\text { business case in terms of costs and benefits" }\end{array}$ & & \\
\hline 2 & $\begin{array}{l}\text { "Ring-fencing areas of uncertainty, } \\
\text { measurement of uncertainty" }\end{array}$ & "Common goal creates realistic vision" & - \\
\hline 3 & - & - & - \\
\hline 4 & $\begin{array}{l}\text { "Change readiness risk management"; "change } \\
\text { is a journey between the current state and the } \\
\text { future, resulting in a powerful business case } \\
\text { for change"; "business costs for not changing" }\end{array}$ & $\begin{array}{l}\text { "Clear picture of future state, vision clarity"; } \\
\text { "interventions fail because of poor direction" }\end{array}$ & $\begin{array}{l}\text { "Building realistic expectations through change } \\
\text { navigation strategy"; "strategic positioning"; } \\
\text { "comprehensive management strategy" }\end{array}$ \\
\hline 5 & $\begin{array}{l}\text { "Measurement, diagnosis, identify inconsistencies } \\
\text { between espoused and actual theories of action, } \\
\text { identifying individual and group defences which } \\
\text { create organisation's problems" }\end{array}$ & - & $\begin{array}{l}\text { "Organisational strategy in enabling } \\
\text { competitive strategy" }\end{array}$ \\
\hline 6 & $\begin{array}{l}\text { "Business case for change, uses Accelerating } \\
\text { Change Approach to assess individual readiness" }\end{array}$ & - & "Strategic management processes" \\
\hline 7 & $\begin{array}{l}\text { "Thorough change readiness assessment } \\
\text { upfront in all projects" }\end{array}$ & "Leadership to imbed the vision for the future" & - \\
\hline 8 & - & - & "Define strategy" \\
\hline $9 “$ & $\begin{array}{l}\text { Assessment of implementation risks"; "depth } \\
\text { of required commitment graded" }\end{array}$ & "Value proposition - purpose" & $\begin{array}{l}\text { "Collective action"; "a differentiated approach } \\
\text { grounded by practical thinking, employing leading } \\
\text { edge tools"; "clear leadership strategy" }\end{array}$ \\
\hline 10 & - & - & - \\
\hline
\end{tabular}

TABle 5

ORGANISATIONAL INFRASTRUCTURE DIMENSION

\begin{tabular}{|c|c|c|c|}
\hline Respondent & $\begin{array}{l}\text { Structure, formal organising arrangements, } \\
\text { technology }\end{array}$ & $\begin{array}{l}\text { Organisational culture, informal organisation, } \\
\text { work unit climate, social factors }\end{array}$ & Leadership philosophy, role and style \\
\hline 1 & - & - & - \\
\hline 2 & "Speed of change" & - & - \\
\hline 3 & - & - & - \\
\hline 4 & $\begin{array}{l}\text { "Organisational alignment"; "supportive } \\
\text { work settings, job redesign, develop required } \\
\text { infrastructure" }\end{array}$ & "Organisational culture review" & $\begin{array}{l}\text { "Leadership and sponsorship, accountability, } \\
\text { credible and visible, legitimises the process" }\end{array}$ \\
\hline 5 & $\begin{array}{l}\text { "Align strategy and organisation, and } \\
\text { employees and the organisation" }\end{array}$ & - & "Decision rights allocation" \\
\hline 6 & $\begin{array}{l}\text { "Structure design"; "technical aspects of } \\
\text { business procedures" }\end{array}$ & $\begin{array}{l}\text { "Appropriate interventions are designed to } \\
\text { take account of prevailing soft aspects such } \\
\text { as culture" }\end{array}$ & $\begin{array}{l}\text { "Change leadership provides insights, attitudes } \\
\text { and behaviours" }\end{array}$ \\
\hline $7 “$ & $\begin{array}{l}\text { Organisational infrastructure"; "technology } \\
\text { application" }\end{array}$ & $\begin{array}{l}\text { "Culture change and its assimilation by } \\
\text { individuals through behaviour" }\end{array}$ & "Management and leadership style" \\
\hline 8 & - & - & $\begin{array}{l}\text { "Leadership systems should ensure skills } \\
\text { development" }\end{array}$ \\
\hline 9 & "Aligning HR infrastructure" & - & "Mobilising and align leaders" \\
\hline 10 & - & - & - \\
\hline
\end{tabular}

Table 6 shows the performance and rewards requirements dimension of the theoretical models. The first column indicates that eight of the respondents stated that 'task requirements, training and competencies, skills development and abilities' formed key components of their change intervention programs, whereas four of the theoretical frameworks identified it as a component. The second column indicates that five of the respondents stated that 'systems, policies and management practices' formed a key component of their change intervention programs, whereas, all five of the theoretical models identified it as a component. The third column indicates that eight of the respondents stated that 'implementation' formed a key component in their change intervention programs, while only one of the theoretical frameworks identified it as a component.

Table 7 depicts the desired targeted outputs phase of the theoretical models. The first column indicates that nine of the respondents stated that 'individuals, their motivation, behaviour, needs and values' formed a key component of their change intervention programs, while all five of the theoretical frameworks identified it as a component. The second column 
TABLE 6

Performance AND ReWARdS Requirements dimension

Respondent Task requirements, training and competencies, skills and abilities

"Project teams"; "delivery vehicles";

"learning is action based"

"Creating competence"; "personal ability to deal with change"

"Work differs at different levels in organisations in terms of complexity and time"

"Develop skills and knowledge, change capability of people"

"Acquiring required skills"
Systems, policies and management practices Implementation
"Project implementation"; "perfecting process implementation"

"Worst first"
"Systems replacement/renewal"; "integration of people, process, technology and measurement aspects"; "aligning processes and systems to reinforce required behaviours"

"Determining additional mechanisms and systems"; "performance management system"; "rewards and punishment systems"

"Systems and processes addressed"; "information systems"; "remuneration and rewards etc"

"Aligning people's processes with implemented solutions, focusing on organisational systems", "working under new performance and rewards requirements"

"Reset incentives to align with share-owner value creation"
"Visible, sustainable, successful implementation"; "choices and tradeoffs navigated and steered as the change unfolds"; "guided by change navigation principles"

"Implementation"; "choices and tradeoffs are

"Accelerating Change transferred to clients for them to take ownership for implementing change, process is monitored

"Implementation teams (clients and consultants)"

"Set detailed metrics"; "make it happen very quickly"

"Implementation - deliverables organised" clearly articulated, implemented and managed"

"Equiping workforce, training, task and competency requirements"; "support programs"; "deployment plans"

TABLE 7

DESIRED TARgETED OUTPUTS PHASE

\begin{tabular}{lll}
\hline Respondent & Individual motivation, inspiration, behaviour, needs and values & Individual and organisational performance outcomes \\
\hline 1 & "Continuous improvement"; "review and confirmation"; "buy-in"; & "Intended versus actual outcomes"; "corrective action ensures that people \\
"a high level of involvement"; "participation of people" & "Grom the process and that needs and objectives of people are met" \\
& $\begin{array}{ll}\text { "Group therapy to share and cope with change"; "communication, } \\
\text { trust, transparency, ability to deal with change"; "program }\end{array}$ & $\begin{array}{l}\text { "Creating the perception that a career is bigger than the organisation and } \\
\text { current change in the organisation"; "limit expectations and deliver" }\end{array}$
\end{tabular}
'ownership' by individuals"

"People differ in their abilities to deal with work at different levels"; "abilities change over time"

"Communication plan"; "identify commited stakeholders"; "supportive and accountable individuals"; "resistance is minimised throughout the process"; "people take ownership"

"Acquire the skills of productive reasoning and feedback"; "people to design and implement their actions"; "individuals unconsciously design and implement actions they do not intend"

"Desired behaviours and attitudes using Accelerating Change Approach, dynamics are managed"

"Project teams and individuals - communication and motivation"; "skills development"; "transitioning people to new roles and behaviours"; "understanding of business case"; "becoming change agents"

"Create the change team"; "celebrate wins"

"Engaging, alignment and mobilisation of key stakeholders"; "team training"; "commitment events"
"Successful results come from the interventions in the work or people area, or from a match between these"

"Enhanced capacity to deal with ongoing future change"; "people side of the change is successfully addressed"; "building more realistic expectations"; "individuals able and willing to perform"

"Maximise shareholder value"; "change - both personal and organisational is key"; "execute competitive strategy"; "develop a more flexible and responsive organisation"

"Human aspects of transformation are explicitly desired outputs", "change management... a key internal competence"

"Focusing at ensuring a sound solution"; "individuals become change agents in their new roles"; "aligning organisation with the required transformed environment, aligning these with individuals"; "ability to function in new roles"

"Build organisational capability"

"Business mobilisation"; "merger integration"; "supply chain transformation"; "shared services implementation"; "custome management transformation"; "integrate program management office"; "ERP implementation" 
indicates that nine of the respondents stated that 'individual and organisational performance and/or outcome' formed a key component in their change intervention programs, while all five of the theoretical frameworks identified it as a component.

Table 8 gives the key measures of implementation success dimension of the theoretical models. The first column shows that the dimension of personal change was not regarded as a key focal area of the intervention programs by two respondents, three respondents implied it as a negligible area, and four respondents regarded it as a key focal area of their intervention programs. The second column of Table 8 explains whether the respondents regarded personal change as a critical measure of their change intervention programs. Two respondents neglected the impact of personal change, two other respondents positively stated that personal change was not a critical measure of their intervention program, and five respondents stated that personal change was a critical determinant of their interventions' outcomes.

\section{DISCUSSION}

According to Beer (1980), a model provides a taxonomy of key organisational dimensions that guide data collection and diagnosis. It can also be useful in providing some understanding of the complex nature of organisational components and would reflect the circularity of causes and effects. The author further states that organisational models are arbitrary, convenient shorthand methods of explaining organisational challenges which can facilitate the process of planning how such challenges can be efficiently dealt with.

Accordingly, the respondents' various 'models', 'approaches', 'frameworks', 'principles' and 'main steps' demonstrate that regardless of how they are referred to, some form of expression is used to explain a method by which organisational phenomena may be understood and, therefore, managed. This explanation concurs with Burke and Litwin's (1992) explanation that change models are not meant to be prescriptive but rather provide a means to diagnose, plan and manage change.
In the context of the present study, the foregoing explanation suggests a systems thinking approach (Beer, 1980) about organisations, in that the change programs are described as complex, interactive, dynamic and interdependent in their application. This explanation suggests that none of the theoretical or respondents' models can be reported as more efficient than the other in dealing with organisational transformation challenges. The tabled results also show that the evaluated intervention programs do not all account for all the components of the dimensions. The results are also consistent with Shirom and Harrison's (1995) emphasis that no single model can fit all diagnostic situations for all client organisations. Caution should therefore be taken not to interpret this to mean that some components are unimportant for some intervention programs. It could, however, be surmised that a particular model is designed for intervention in specific targeted areas, both in theory and in practice.

The results in Tables 4 to 6 reflect that personal change is a subtle component, which emerges in reaction to intervention in other organisational areas. This observation is reinforced by Beer's (1980) assertion that organisations are formed to achieve purposes which individuals alone cannot achieve, and individuals join organisations to achieve personal goals they cannot achieve by themselves. An intervention into any other organisational area will eventually have a direct or indirect impact on organisational members. Argyris' (1985, p.3) attests that organisational members "are the carriers of defensive routines, and organisations are the hosts". It can be inferred therefore that personal change is not a distinct dimension which organisational transformation programs can deliberately focus on as an intervention area. This inference supports both the premised and the theoretical reasons for ineffectual change intervention programs (Erfat, 1998; Human, 1996; Manning, 1996; Werth (1994).

The first column of Table 7 reports on the individual motivation, behaviour, needs and values' component. The results show that personal change elements are implied as integral to all five of the theoretical models, and in nine of the

TABle 8

\section{KEY MEASURES OF IMPLEMENTATION SUCCESS DIMENSION}

\begin{tabular}{|c|c|c|}
\hline Respondent & $\begin{array}{l}\text { Personal change as a key focal area of an organisational change } \\
\text { intervention }\end{array}$ & $\begin{array}{l}\text { Personal change as as critical determinant of the success or failure } \\
\text { of an organisational change intervention }\end{array}$ \\
\hline 1 & Personal change is not stated as a focal area & $\begin{array}{l}\text { "Sustained personal change is a requirement for success in change } \\
\text { management" }\end{array}$ \\
\hline 2 & Identified principles "impact on change at the individual level" & $\begin{array}{l}\text { Personal change is not explained as impacting or not impacting on the } \\
\text { intervention }\end{array}$ \\
\hline 3 & $\begin{array}{l}\text { "Personal change is accomodated if the people component is } \\
\text { addressed"; "if intervention is on the work component, no personal } \\
\text { change is likely to occur"; it "may occur even where interventions fail" }\end{array}$ & "Personal change is not a requirement for the success of the intervention" \\
\hline 4 & Personal change is "an integral part of the intervention" & $\begin{array}{l}\text { Personal change is explained as "a critical determinant of the } \\
\text { intervention's success" }\end{array}$ \\
\hline 5 & $\begin{array}{l}\text { Personal change is not stated as a focal area of the intervention } \\
\text { but "change - both personal and organisational is key" }\end{array}$ & $\begin{array}{l}\text { "Personal change is a critical determinant that impacts the effectiveness } \\
\text { of both competitive and organisational strategy" }\end{array}$ \\
\hline $6 “$ & $\begin{array}{l}\text { Personal change is a very critical component of our transformation } \\
\text { approach" }\end{array}$ & $\begin{array}{l}\text { "Human aspects of transformation are explicitly defined as key measures } \\
\text { to define implementation success" }\end{array}$ \\
\hline 7 & $\begin{array}{l}\text { The "personal change component is most relevant in the individual } \\
\text { alignment" }\end{array}$ & "Personal change has an impact on the outcome of the intervention" \\
\hline $8 “$ & $\begin{array}{l}\text { Relying on individual change is a dangerous thing to do in a major } \\
\text { change program" }\end{array}$ & "Personal change is not a key driver" \\
\hline 9 & $\begin{array}{l}\text { Personal change "is considered at task requirements level, but it is not } \\
\text { a focal area due to size of the intervention" }\end{array}$ & $\begin{array}{l}\text { Personal change is not explained as impacting or not impacting on the } \\
\text { intervention }\end{array}$ \\
\hline 10 & Consultant does "not consult at a personal level" & Consultant does "not consult at a personal level" \\
\hline
\end{tabular}


respondents' intervention programs. Again, the second column of Table 7 shows that all five of the frameworks and nine of the respondents' regard 'individual and organisational performance' as a desirable outcome of an organisational intervention program. This observation emphasises and strongly supports this study's rationale that personal change elements, though not forming the primary focus of intervention programs, are integral to those programs. They deserve to be explored and developed or emphasised as distinguishable focus areas in organisational change interventions. The observation also concurs with the 'high performance model' (Pickering \& Matson, 1992) which asserts that individuals have an inherent need to make a meaningful contribution to organisational performance, because, the 'individual' represents the 'people' component of organisational key dimensions. This is especially relevant if individuals' performance weighs as an equal measure of organisational performance outcomes. This explanation further strengthens the theoretical importance of the personal change dimension as consisting of catalytic organisational success factors (Daft \& Lengel, 1998; Manning, 1997; Quinn, 1996; Veldsman, 1998).

The first column of Table 8 shows that three of the respondents indicated that personal change is not a key focal area of an intervention, but gets indirectly impacted on by the change intervention processes taking place in any of the organisational areas. Two of the respondents indicate that personal change is not a key focal area of their intervention programs. This implies that, overall, five respondents regard personal change as a negligible area of their intervention programs as against four respondents who positively indicated that personal change is an 'integral' part, though not a 'key focal area' of their organisational change processes. One respondent indicated that he does 'not consult on a personal level'. This response suggests that the question may have been misinterpreted. This finding also supports the theoretical explanations of why change interventions are ineffective, as argued by Erfat, (1998), Human, (1996), Manning, (1996) and Werth, (1994).

The second column of Table 8 shows that two of the respondents indicated that the impact of personal change on the performance outcome of their intervention programs is negligible. Two respondents positively stated that personal change is not a critical measure of their intervention programs. The overall implication is that personal change is not used to measure the performance outcome of four change intervention programs, as opposed to five who do. The one respondent who does not consult on a personal level, may have, once again, misinterpreted the research question. The inference therefore is that only half of the intervention programs emphasise personal change as a critical performance measure of their interventions' implementation outcome.

In summary, it is noteworthy that only one of the researched model's components corresponded with all of the theoretical models' components used in the formulation of the categories and dimensions. Even more striking is that this model is one of the five intervention programs that regarded personal change as a key performance measure of an intervention's success. A generalised interpretation is that a comprehensive intervention program is likely to impact strongly on personal change elements.

The 2002 world competitiveness rankings show a slight improvement in South Africa's economic performance compared to that of 2001 (47 in 2001 and 46 in 2002) (WCY, 2002). The persistent imperative for sustainable organisational productivity and national competitiveness reinforces the need for congruent personal and organisational goals to effect a significant improvement in the country's economic performance. It is thus recommended that organisational change intervention programs must incorporate a deliberate emphasis on personal change and its elements in order to explore the organisational members' latent potentialities in leading organisations to economic excellence.

Argyris (1985; 1990; 1991) emphasises that organisational and individuals' goal incongruence requires a move away from defensive ways of reasoning. This could be achieved by teaching people how to recognise the reasoning they use when they design and implement their actions, from which they can identify inconsistencies between their intended and actual theories of action, which eventually contribute to organisations' problems. Productive reasoning strategies must be employed to reshape individuals' 'master programs' at their cognitive levels to achieve continuous improvement which would result in personal change (Forsha, 1992a, 1992b).

It is also imperative for academic tertiary institutions to design and structure their change management curricula such that they focus on theories and extensive practices which emphasise the significance of personal change in organisational change efforts. This would result in a heightened awareness of the importance of personal change among scholars, should they endeavour to focus their careers on organisational development and transformation management. Practising professionals should also increase their emphasis on personal change, and integrate it as a critical measure of their change intervention programs' outcomes. It could serve as catalytic in breaking down resistance to change which seems prevalent in South African organisations (Birkin, 1997; Erwin, 1998; Hall \& Maritz, 1997; Mbigi, 1997; Veldsman, 1996). Neglecting it could imply a continuous undermining of the efforts expended in organisational change interventions.

The findings of this study further confirm that personal change elements are intangible (Block, 1996; Czander, 1993; Diamond, 1986; Novelli, et al.1995; Senge, 1990), and cannot be manipulated and measured in visible conventional organisational methods. This verification emerges as a deficiency of the study in that, even though these elements have been argued as critical organisational concerns, the lack of their concrete presence may discourage initiatives towards developing them into determinant organisational factors. The difficulty that accompanied isolating them from the identified general and reported organisational frameworks could further undermine their importance in impacting on organisational success factors.

Further research could therefore focus on exploring Czander's (1993) recommendation to apply psychoanalytic theories to organisational theories. The use of focus group interviews as a different research design could provide a platform for debate, and perhaps yield increased clarity on the phenomenon. The aim would be to investigate means by which personal change elements can be explored to assist the development of the idealised change intervention programs. Other qualitative methods, like in-dept face-to-face interviews, life histories (autobiographies, biographies and particularly diaries) and participant observation would be also very helpful in future research of the phenomenon. Additionally, quantitative methods, e.g. surveys and questionnaire based on qualitative findings and insights produced by the present study could also be utilised. Finally, George (2000) cautions that a growing body of literature suggests that feelings are intricately bound up in the ways in which people think and subsequently behave. There is therefore a need for SA organisations to refocus and concede that the individuals' cognitive and affective domains have a significant influence in organisational members' decision-making processes to support or not to support, organisational goals. 


\section{REFERENCES}

Annels, M. (1996). Grounded theory method, part1: Within the five moments of qualitative research. Nursing Inquiry, 4, 120-129.

Argyris, C. (1985). Strategy, change and defensive routines. London: Harvard University.

Argyris, C. (1990). Overcoming organisational defences: Facilitating organisational learning. Boston: Allyn and Bacon.

Argyris, C. (1991). Teaching smart people how to learn. Harvard Business Review, May-June, 99-109.

Babbie, E \& Mouton, J. (Eds) (2001). The practice of social research. Cape Town: Oxford.

Backman, K. \& Kyngas, H.A. (1999). Challenges of the grounded theory approach to a novice researcher. Nursing and Health Sciences, 1, 147-153.

Bartlett, C.A. \& Ghoshal, S. (1995). Rebuilding behavioural context: Turn process reengineering into people rejuvenation. Sloan Management Review, Fall, 11-23.

Beer, M. (1980). A social systems model for organisation development. In T.G. Cummings. Systems theory for organisation development. New York: Wiley

Beer, M., Eisenstat, R.A. \& Spector, B. (1990). The critical path to corporate renewal. Boston, MA: Harvard Business School.

Berg, B.L. (2001). Qualitative research methods for the social sciences ( $4^{\text {th }}$ ed.). Boston: Allyn \& Bacon.

Birkin, M. (1997). How to build the unlimited company in South Africa. Management Today, 13 (6), 20-26.

Block, P. (1996). Stewardship: Choosing service over self interest. San Francisco: Berrett-Koehler.

Bretherton, D. (1993). Personal change. Emergency Librarian, 20(3), 30-34.

Bridges, W. (1996). Transitions: Making sense of life's changes. London: Nicholas Brealey.

Buckman, J.M. (1996). Resistance to change. Fire Engineering, 149 (5), 10-12

Burke, W.W. \& Litwin, G.H. (1992). A causal model of organisational performance and change. Journal of Management, 8 (3), 523-546.

Cooper, R. \& Markus, M.L. (1995). Human reengineering. Sloan Management Review, Summer, 39-50.

Coulson-Thomas, C. (1992). Corporate transformation: The people requirement. Journal of European Industrial Training, 16 (5). 11-15.

Covey S.R. (1991). Principle-centred leadership. New York: Simon \& Schuster.

Covey, S.R. (1993). Transforming a swamp. Training \& Development, May, 43-46.

Cutcliffe, J.R. (2000). Methodological issues in grounded theory. Journal of Advanced Nursing, 31 (6). 1476-1484.

Czander, W.M. (1993). The psycho-dynamics of work and organisations: Theory and application. New York: Guilford.

Daft, R.L. \& Lengel, R.H. (1998). Fusion leadership: Unlocking the subtle forces that change people and organisations. San Francisco: Berrett-Koehler.

Diamond, M.A. (1986). Resistance to change: A psychoanalytic critique of Argyris and Schon's contributions to organisational theory and intervention. Journal of Management Studies, 23 (5), 543-562.

Edwards, M. \& Sen, G. (2000). NGO'S, social change and the transformation of human relationships: A 21st century civic agenda. Third World Quarterly, 21 (4), 605-616.

Efrat, Z. (1998). Personal productivity: Beat office politics. Productivity SA, July/August, 11-13.

Erwin, A. (1998). Competitiveness and wealth creation: A government perspective. Management Today, August, 14-18.

Forsha, H.I. (1992a). The pursuit of quality through personal change. Part1. Quality Progress, January, 57-61.

Forsha, H.I. (1992b). The pursuit of quality through personal change. Part 2. Quality Progress, February, 61-64.

George, M.J. (2000). Emotions and leadership: The role of emotional intelligence. Human Relations, 53 (8), 1027-1055.
Ghoshal, S. \& Bartlett, C.A. (1996). Rebuilding behavioural context: A blueprint for corporate renewal. Sloan Management Review, Winter, 23-36.

Hall, J. \& Maritz, F. (1997). Leadership: Turning potential into productivity. Management Today, 13 (6), 27-31.

Halton, W. (1994). Some unconscious aspects of organizational life: Contributions from psychoanalysis. In A. Obholzer \& V.Z. Roberts (Eds), The unconscious at work: Individual and organisational stress in the human services by the Members of the Tavistock Clinic Consulting to Institutions Workshop (pp.11-18). London: Routledge.

Hey, K.R. \& Moore, P.D. (1998). The caterpillar doesn't know: How personal change is creating organisational change. New York: Free Press.

Hersey, P. \& Blanchard, K.H. (1993). Management of organizational behaviour: Utilizing human resources ( $6^{\text {th }}$ ed.) New York: Prentice Hall.

Herzberg, F. (1971). Work and the nature of man. London: Staples.

Hicks, C.E., Rush, J.E. \& Strong, S.M. (1977). Content analysis. In E. D. Dym (Ed.) Subject and information analysis. New York: Marcel Dekker.

Human, L. (1996). Diversity during transformation. HRM, 12 (2), 4-12.

Huysamen, G.K. (1994). Methodology for the social and behavioural sciences. Halfwayhouse: Southern.

Ivancevich, J.M. \& Matteson, M.T. (1993). Organizational behavior and management: Instructor's edition (3 ${ }^{\text {rd }}$ ed.). Boston: Irwin.

Kerlinger, F.N. \& Lee, H.B. (2000). Foundations of behavioural research ( $4^{\text {th }}$ ed.). New York: Harcourt College.

Long, S. \& Newton, J. (1997). Educating the gut: Socio-emotional aspects of the learning organisation. Journal of Management Development, 16 (4), 284-301.

Manning, T. (1996). Three steps to the future. HRM, 12 (8), 8-9.

Manning, T. (1997). Radical strategy: How South African companies can win against global competition. Sandton: Zebra.

Marshak, R.J. (1993). Managing the metaphors of change. Organizational Dynamics, 22 (1), 44-46.

Mbigi, L. (1997). Ubuntu: The African dream in management. Randburg: Knowledge Resources.

Mbigi, L. \& Mandela, M. (1998). Collective learning: Skill democratisation. People Dynamics, November/December, 38-44.

Mbigi, L. \& Maree, J. (1995). Ubuntu: The spirit of African transformation management. Randburg: Knowledge Resources.

Mosse, J. (1994). Introduction: The institutional roots to institutions. In A. Obholzer \& V.Z. Roberts (Eds), The unconscious at work: Individual and organizational stress in the human services by the Members of the Tavistock Clinic Consulting to Institutions Workshop (pp.1-8). London: Routledge.

Nadler, D.A. \& Tushman, M.L. (1980). A model for diagnosing organisational behaviour. Organisational Dynamics, 9, Autumn, 11-28.

Novelli, L., Kirkman, B.L. \& Shapiro, D.L. (1995). Effective implementation of organisational change: An organisational justice perspective. In C.L. Cooper \& D.M. Rousseau (Eds), Trends in organisational behaviour, Volume 2, (pp.15-36). New York: Wiley.

Obholzer, A. (1994). Afterword. In A. Obholzer \& V.Z. Roberts (Eds), The unconscious at work: Individual and organizational stress in the human services by the Members of the Tavistock Clinic Consulting to Institutions Workshop (pp.206-210). London: Routledge.

Pickering, J.W. \& Matson, J.E. (1992). Why executive development programs (alone) don't work. Training \& Development, 46 (5), 91-95.

Quinn, R.E. (1996). Deep change: Discovering the leader within. San Francisco: Jossey-Bass.

Robertson, P.J., Roberts, D.R. \& Porras, J.I. (1993). Dynamics of planned organisational change: Assessing empirical support for a theoretical model. Academy of Management Journal, 36 (3), 619-634. 
Roller, E., Mathes, R. \& Eckert, T. (1995). Hermeneuticclassificatory content analysis: A technique combining principles of quantitative and qualitative research. In U. Kelle, G. Prein \& K. Bird (Eds), Computer-aided qualitative data analysis: Theory, methods and practice (pp.167-176). London: Sage.

Senge, P.M. (1990). The fifth discipline: The art and practice of learning organisations. New York: Doubleday.

Shirom, A. \& Harrison, M.I. (1995). Diagnostic models for organisations: Toward an integrative perspective. In C.L. Cooper \& D.M. Rousseau (Eds), Trends in organisational behaviour, Volume 2 (pp.85-107). New York: Wiley.

Silverman, D. (2000). Doing qualitative research: A practical handbook. London: Sage.

Stokes, J. (1994). Institutional chaos and personal stress. In A. Obholzer \& V.Z.

Roberts (Eds), The unconscious at work: Individual and organizational stress in the human services by the Members of the Tavistock Clinic Consulting to Institutions Workshop (pp.121-128). London: Routledge.
Swart, J. \& Van Vuuren, L.J. (1998). Cognitive style and the interpretation of organisational change. Journal of Industrial Psychology, 24 (3), 22-31.

The World Competitiveness Yearbook (WCY). (2000). Lausanne: IMD International.

The World Competitiveness Yearbook (WCY). (2001). Lausanne: IMD International.

The World Competitiveness Yearbook (WCY). (2002). Lausanne: IMD International.

Tonkin, A. \& Alfred, M. (1994). Competitiveness in perspective. People Dynamics, 12 (12), 25-35.

Veldsman, T.H. (1996). Managing large scale change management successfully: Why does large scale organisational change fail so frequently? HRM, 12 (3), 23.

Veldsman, T.H. (1998). The making of a people miracle. Management Today, 14 (2), 35.

Veldsman, T.H.(2002). Into the people effectiveness arena: Navigating between chaos and order. Johannesburg: Knowledge Resources.

Werth, R. (1994). Is there life after change? HRM, May, 12-13.

Yadavalli, L. (1998). International competitiveness: Where we stand. Productivity SA, January/February, 13-15. 